\title{
Correction to: Pediatric Blood Cultures and Antibiotic Resistance: An Overview
}

\author{
Chand Wattal $^{1} \cdot$ Neeraj Goel ${ }^{1}$
}

Published online: 12 March 2020

(C) Dr. K C Chaudhuri Foundation 2020

\section{Correction to: Indian J Pediatr (2020) 87(2):125-131} https://doi.org/10.1007/s12098-019-03123-y

The article Pediatric Blood Cultures and Antibiotic Resistance: An Overview, written by Chand Wattal and Neeraj Goel, was originally published electronically on the publisher's internet portal (currently SpringerLink) on 21 December 2019 with open access. With the author(s)' decision to step back from Open Choice, the copyright of the article changed on 26 February 2020 to (C) Dr. K C Chaudhuri Foundation 2019 and the article is forthwith distributed under the terms of copyright.

The online version of the original article can be found at https://doi.org/ 10.1007/s12098-019-03123-y

Chand Wattal

chandwattal@gmail.com

1 Department of Clinical Microbiology \& Immunology, Sir Ganga Ram Hospital, Rajinder Nagar, New Delhi, India 